\title{
Presidential Address
}

\section{DELIVERING MENTAL HEALTH SERVICES TO THE PEOPLE OF KERALA -NEED FOR A BALANCING ACT}

\author{
Harish M Tharayil, Professor of Psychiatry, Govt Medical College, Kozhikode \\ Corresponding address:drharishmt@gmail.com
}

At the outset, I wish to briefly draw your attention to one of the international frameworks that play a role in shaping our speciality first. Then I shall tell you a few facts about the mental health scenario in our state. I shall also share with you some insights based on data collected informally from our younger colleagues. Based on all these, I have more questions than answers. I believe these questions and answers should play a crucial role in any plans or proposals that we wish to enact in future. I sincerely hope we can do a successful balancing act to deliver quality services to our population.

\section{International framework (WHO}

Comprehensive Mental Health Action Plan (CMHAP) 2013-'20)

\section{Vision}

A world in which mental health is valued, promoted, and protected, mental disorders are prevented, and persons affected by these disorders are able to exercise the full range of human rights and to access high-quality, culturally appropriate health and social care in a timely way to promote recovery, all in order to attain the highest possible level of health and participate fully in society and at work free from stigmatization and discrimination.

\section{Objectives}

To strengthen effective leadership and governance for mental health

1. To provide comprehensive, integrated and responsive mental health and social care in community-based settings

2. To implement strategies for promotion and prevention in mental health

3. To strengthen information systems, evidence and research for mental health

The following cross-cutting principles are to be taken care of during planning, implementation and evaluation of any programs or plans;

- Universal Health Coverage

- Human Rights

- Evidence-based Practices

- Life-course Approach

- Multisectoral approach

- Empowerment of persons with mental disorders and psychosocial disabilities

Individual countries were expected to formulate appropriate policies and programs to achieve the targets of the MH Action Plan 2013 to 2020.

Please cite this article as: Tharayil HM. Delivering mental health services to the people of Kerala -Need for a balancing act (Presidential address). Kerala Journal of Psychiatry 2019;32(1):1-9 doi: 10.30834/KJP.32.1.2019.175 
Mental Health Sector in India - insights from National Mental health survey (NMHS)

National Institute of Mental Health and Neurosciences (NIMHANS) has conducted a nation-wide survey in 2015-16 to throw light on the current state of mental health in our country. The objectives of the study were to find prevalence and patterns of mental illnesses, and their outcomes using a house to house survey in selected states. They also looked at the mental health systems that deliver care to patients and the human resources available. I am not going to describe the details of the survey but to compare Kerala with national figures.

\section{Comparison of Kerala to other states in NMHS}

In Kerala, the household survey was carried out in selected clusters of selected taluks of 3 districts - Thrissur, Palakkad and Pathanamthitta. The sample surveyed is more or less similar to the population of the state on demographic characteristics. Conditions like dementia and other organic illnesses and disorders of eating, sexual functions, sleep and personality were not covered in this work. Data collection in Kerala also excluded persons below 18 years of age.

Patterns and prevalence of psychiatric disorders (See Table.1)

- Slightly higher mental illness prevalence across categories in Kerala compared to the national figure

- Slightly lower use of other substances except for tobacco and alcohol

- Comparable prevalence of alcohol use disorders

- Tobacco use is much less than the national figure $(7 \%)$
- Prevalence of Severe Mental disorders (SMDs) in Kerala is less than half of the national figure. (According to the study team, this could be more likely be due to the low sensitivity of the tool (MINI) used. But if this is the case, it should have affected all states and all conditions). But mood disorders - both depression and bipolar affective disorder (BPAD) have higher rates in our state.

- There is a significantly higher prevalence of Neurotic and stress-related disorders, including phobias and OCD.

- The trend of higher psychiatric morbidity in lower socio-economic status (SES)

- Epilepsy- 0.38\%

- Suicide rate (NCRB-2014)

- 23.9/one lakh (India 10.6)

- Males-40.1 (India 14.3)

- Females 11.7 (India 7.24)

- Overall high suicide risk (NMHS data) $2.23 \%$

Mental Health care systems and human resources in Kerala

MH Care facilities - Government

- All 14 districts have running District Mental health Program (DMHP)

- Government Mental Health Centres (GMHCs)-One out of these three upgraded to Centre of Excellence as given in NMHS report. (Referring to the Institute of Mental Health \& Neurosciences (IMHANS) which has collaborated for this survey with NIMHANS Bangalore). But IMHANS is no more attached to GMHC, Kozhikode or Government Medical College, Kozhikode. I do not intend to discredit IMHANS or its activities. They have been the single 
agency responsible for implementing community mental health services in four districts of Kerala - two of which are among the most backward ones, Wayanad and Kasaragod. This initiative will lead to the spread of DMHP to all districts, even without central funding. We should remember that five DMHPs were started with central funding. IMHANS also pioneered the concept of screening children for developmental disabilities - a project which was scaled up by the state government. They have also started MPhil courses in Clinical Psychology and Psychiatric Social work. Besides, they have started Diploma in Psychiatric Nursing course for nurses after General Nursing \& Midwifery (GNM) Diploma.

- Government Medical Colleges with Psychiatry Departments -9
Super-speciality hospitals -8 (?)

- District Hospitals (DHs) $-38-47.37 \%$ of DHs provide psychiatric outpatient/ inpatient care

- Total no. of psychiatric beds-1962 (i.e. 5.87 per one lakh)

- Taluk Head Quarters Hospitals (THQHs)-79- 16.46\% of all THQHs

- provide Psychiatric services

- Mobile mental health units-22

- Day-care facilities-43

- De-addiction units-66

- Vocational training units-10

- Six sheltered workshops -6

- Long stay facilities-146

MH Care facilities -Private

- Super-speciality - 24

- Medical Colleges- 22

- Hospitals -1150

Table 1. Comparison of mental illness burden between India \& Kerala

\begin{tabular}{|l|l|l|l|l|}
\hline \multirow{2}{*}{ Disorder } & \multicolumn{2}{l|}{ Lifetime } & \multicolumn{2}{l|}{ Current } \\
\cline { 2 - 6 } & India & Kerala & India & Kerala \\
\hline $\begin{array}{l}\text { Mental and behavioural problems due to } \\
\text { psychoactive substance use }\end{array}$ & 22.4 & 10.12 & & \\
\hline Alcohol use disorder & & & & \\
\hline Other substance use disorder (except tobacco) & 4.65 & 4.82 & & \\
\hline Tobacco use disorders & 0.57 & 0.08 & & \\
\hline Schizophrenia, other psychotic disorders & 20.89 & 7.22 & & \\
\hline Mood (Affective) disorders & 1.4 & 0.6 & 0.42 & 0.19 \\
\hline Bipolar Affective Disorders & 5.6 & 2.84 & 6.22 & 2.62 \\
\hline Depressive Disorder & 0.5 & 0.30 & 0.72 & 0.17 \\
\hline Neurotic \& stress related disorders & 5.3 & 2.68 & 5.54 & 2.49 \\
\hline Phobic anxiety disorders & 3.7 & 3.53 & 5.63 & 5.43 \\
\hline Other anxiety disorders & 1.91 & 3.19 & & \\
\hline Obsessive Compulsive Disorder & 1.3 & 1.15 & 1.9 & 1.62 \\
\hline
\end{tabular}




\section{Availability of MH Care personnel}

We have around 400 to 500 practising psychiatrists in Kerala at present. Availability of allied professionals like Clinical Psychologists (CPs), Psychiatric social workers (PSWs), Psychiatric nurses etc. are also higher than the national average, though inadequate compared to developed nations. For example, the USA has a ratio of ten psychiatrists per one lakh population. Scandinavian countries have double or higher than this. Australia has around 13. In NMHS the number per lakh varied from 0.05 in Madhya Pradesh to 1.2 in Kerala, which is the highest Ratio (National ratio is only 0.295).

\section{Number of PG seats}

- MD (Psychiatry) -40

- Dip NB at four each at GMHCS and Lourdes Hospital, Ernakulam

- DPM discontinued except at Thiruvananthapuram Medical college \& Pushpagiri Institute of Medical sciences

It seems that a higher number of female doctors are opting for Psychiatry. Currently, the percentage of female residents is $62.5 \%$. Has both positive and some negative effects! This could be the result of a higher number of female medical graduates.

\section{Agencies working in the state under Govt, Private and NGO ownership}

- Govt agencies under Health \& Family Welfare Department, Govt. of Kerala

- Directorate of Health Services (DHS)

- Directorate of medical education (DME)

- National Health Mission

- Directorate of Insurance medical services (Under labour department)

- Other Govt agencies
- Social Security Mission under Ministry of social justice

- Agencies under Education, Home, Prisons and correctional dept, Excise

- Private agencies

- Private medical colleges

- General hospitals owned by corporate/ Trusts

- Non-Govt agencies of varying affiliations run by many agencies

Percentage of Health budget allocated for Mental Health is only1.16\% out of which only $0.18 \%$ is utilised.

Another issue NMHS highlight is the poor coordination between different agencies.

\section{Problems}

- High suicide rates

- Ageing population

- High migration to other states / Presence of a good number of migrant labourers from other states countries (not from NMHS)

- Weakening social ties

- High rates of alcohol use

- Emerging issues like high prevalence of Substance Use Disorders (SUDs) among youth

High prevalence of Common Mental Disorders (CMDs) may be leading to increased utilisation of general health service resources by this group. This may lead to a strain on general physicians and family practitioners. Many of them would also be frequent users of the AYUSH systems.

One reasonable conclusion about Kerala, according to NMHS, is: "Kerala is ahead of other states in most health and development indicators and desirable population 
Table2. Comparison of treatment gap between Kerala \& India

\begin{tabular}{|l|l|l|}
\hline & Kerala & National \\
\hline Any Psychiatric illness & $84.17 \%$ & 84.5 \\
\hline Substance use disorders & & 91 \\
\hline Alcohol use disorder & $88.1 \%$ & 86.3 \\
\hline Tobacco use disorder & & 91.8 \\
\hline others & & 72.3 \\
\hline severe mental disorder & $62.5 \%$ & 73.6 \\
\hline Psychotic disorders & $50.0 \%$ & 75.5 \\
\hline Mood disorders & & \\
\hline Bipolar disorder & $66.67 \%$ & 70.4 \\
\hline Depressive disorder & $86.7 \%$ & 75.5 \\
\hline Neurotic disorders & $85.14 \%$ & 84 \\
\hline Panic Disorder & & \\
\hline common mental disorders & $86 \%$ & 85 \\
\hline Neurotic & & \\
\hline MDD & $86.7 \%$ & 85.2 \\
\hline
\end{tabular}

characteristics. It has a comparatively wellorganised public health system. It has a mental health policy in place. Functioning DMHPs are there in all 14 districts".

\section{Treatment Gap in Kerala}

Treatment gap was assessed during house visits. Any patient who has a history of mental illness (Schizophrenia, BPAD) and not on treatment for the past one year was considered as one with a treatment gap.

- Treatment gap $=84.17 \%$

- Treatment gap continues to be high; more so for substance use and CMDs

- The median duration of illness; 84 months (1 - 480)

- The median interval between onset and consultation -3 months $(1-60)$

- The median number of treatment providers consulted $3(1-15)$

- Most recent being govt Dr in 31.8\%
- The median duration of being in treatment 32 months ( 1 - 449)

\section{Issues faced by our young colleagues}

Next, I am drawing your attention to some data we have collected from the Psychiatrists who have passed out between 2011 to 2019 working in Kerala. We could contact 85 doctors; 42 males and 43 females. Sixty-two of them had passed out from Govt colleges and 23 from private colleges. Eleven of them reported difficulty to find the first job. Six reported further difficulty to change from the first job to another one. Thirty-nine of them were working under DHS, 25 in private hospitals. Nine were in private medical colleges and two under DME.

Seventy-two of them had started a private practice in addition to jobs. The average salary was around Rs 70 to $80 \mathrm{k}$ for the most. Many said they join the government sector as there is job security, though they are not in psychiatrist posts and have less chance to see psychiatry cases during their work.

Majority of them reported they were using psychosocial methods in addition to medications. They felt the course does impart sufficient knowledge and skill to do this, though I am a bit sceptical. But they said there has to be some agreement on how to charge for such service and some minimum fees has to be fixed by professional bodies on an hourly basis.

Finally, I wish to draw your attention to the following facts. What can we, as a body of professionals, do to address these issues and provide balanced care?

\section{Medical Education}

Undergraduate Level: We are yet to succeed in our efforts to add Psychiatry as a subject with the examination. 
Postgraduate Level: Number of seats has increased, and it is time for us to think of higher-level specialisation within Psychiatry.

\section{Options for Higher training and}

\section{subspecialisation}

Opportunities for higher training needs to be increased. Unlike in the west, Indian Psychiatric Society (IPS) does not have any say in deciding the course content or training pattern of post-graduate trainees. We also do not have such courses after MD. Very few centres allow students to have clinical postings in the subspecialties. Subspecialties like Addiction, Child and adolescent, Geriatric and Forensic are common to all the bodies. Fellowships or FNB programs can be started in these areas. DM has been launched in Geriatric, Child and adolescent and Addiction at NIMHANS and few other centres. The prospects of these courses have to be looked at before starting such courses. Our young colleagues also suggested the same ideas - that courses should be started in the following specialities in Kerala - Child and adolescent psychiatry, C / L Psychiatry, Geriatrics and Addiction.

We have a better ratio of psychiatrist to population, but we are yet to reach a level of at least 1: 10, which is seen in many developed countries. It is reflected Lower treatment gap in our state for major mental illness. The treatment gap varies from $62.5 \%$ for severe mental illness, 50\% for schizophrenia and $86 \%$ for the minor ailments. It must be noted that we also have the highest per capita availability of other mental health professionals.

This means that there is much more need for increasing awareness among various sections of the society regarding basic facts;
- There are effective treatments available for all mental and behavioural disorders, including misuse of alcohol and other substances.

- Treatments for these conditions have to be taken as early as possible as outcomes are better with an earlier start of treatment

- Most of these treatments need a long duration of medications and follow up

Opportunities for increasing awareness and case finding

We need to improve case identification through better education of community workers and other medical doctors. Community workers like Accredited Social Health Activists (ASHA) need to be given training in case identification and in ensuring proper follow up. Regarding awareness among doctors, we need to have better relationships and build inroads within other professional organisations like Indian Medical Association (IMA), Association of Physicians India (API), organisations of other specialists and family physicians. More than just lip service, we must positively identify our members with such skills and promote them as our ambassadors.

We have to offer regular, well-conducted awareness programs in liaison with various governmental and Non-Government Organisation (NGO) agencies and Local Self Government (LSG) bodies. Observance of important international days like Suicide prevention day (September 10), Alzheimer's disease day (September 21), World mental health day (October 10), Disabled persons day (December 3), Down's syndrome day (March 21), Autism day (April 2), Schizophrenia day (May 24), Day against Tobacco use (May 31), Day against drug abuse (June 26), etc. are excellent occasions for planning joint 
activities. It would be good if such activities are initiated at the state level, and events at each district are compiled. We should have quarterly Executive Committee (EC) meetings to chalk out programs for the next quarter.

\section{Better coordination between different agencies working in mental health care}

We need to have good coordination at district level between DMHP, Guilds and academic centres within that district. The IPS EC members from that district can help in this coordination. It would be helpful if State EC members are selected from each region through the guilds.

School Mental Health Promotion is an area needing such an effort. DMHPs are supposed to be doing this, but they may not have time or personnel. Our members through guilds can volunteer for these activities.

Other agencies worth collaborating with are Nirbhaya, Bhumika, Other such entities under Kerala Social Security Mission, Social Welfare Department, Mahila Samakhya Society, Childline, Kerala State Legal Services Authority (KeLSA).

\section{Issues raised by those under DHS}

\section{Low starting pay}

There is a long waiting time to become Junior Consultants (JC). Many of them continue as Assistant Surgeons even though they had PG while joining service. They say that DHS has to be strengthened with more psychiatrists. All THQH should have the post of psychiatrists and the ratio of Consultant: JC must be improved. Such issues for those under DHS need to be addressed by liaising with KGMOA.
Our recently passed out colleagues face a lot of difficulties in earning a stable income even after possessing the necessary qualifications and skills needed to practice the speciality.

Delay in Public Service Commission (PSC) recruitment is another issue bothering young graduates. It is more than seven years since PSC has called application for the post of Assistant Professors. Government decision to recruit those without PG degree as Lecturer can only reduce the availability of MCI approved teachers and further complicate the issues by court cases between those in service.

\section{Private sector}

Many hospitals are not keen to appoint psychiatrists due to less revenue. Only parttime service needed for many places. Most are willing to be appointed on sharing of revenues basis than a fixed salary. There is no job security which creates difficulty in planning long term financial goals.

They felt more awareness is needed among the public. Many of our esteemed members are already doing a lot in this area using media, including social media. While doing such awareness classes, we have to be careful not to play to the gallery and authorise controversial or unscientific treatments. Only evidencebacked treatments should be endorsed by qualified professionals. The tendency to over medicalise normal distress and offering superficial formulas and tips to solve complex issues also has to be guarded against. Some highlighted the high number of frauds / unqualified practitioners in this area which creates harm to patients in some cases. Measures to reduce stigma for mental illness still must be strengthened. Better enforcement of laws and regulatory framework needed 
We need to impart necessary skills to our psychiatrists to improve retention of cases that they treat. Improving adherence to medications and psychosocial treatments, including rehabilitation, must be done on an ongoing basis.

\section{Legal aspects}

New laws like the Mental Health Care Act (MHCA) may create more issues, though not in the forefront at present due to delay in implementation. A lot of coordination and integration is needed among departments of Health, Social Justice, Police in smooth handling of provisions of the Act as we do not have a category of professionals like the Accredited Mental Health Professionals of the UK.

Mental health care facilities working in NGO /voluntary sector like rehabilitation homes are to be under MHCA. But how far they can comply with the legal requirements has to be seen.

The issue of wandering patients: Such persons should be produced at the nearest government health care facility and his physical problems addressed. Subsequently, they should be sent to the nearest government mental health care facility with a report of physical condition. These procedures are not usually followed. It is not clear who is the responsible authority to oversee how a mentally ill person is taken to a mental health care facility - whether police can be told it is their duty. What to do if they refuse?

Still, we do not have the Review boards in districts. If only three MHRBs are there in Kerala, a lot of such transportations would be needed.

Sec 104 says about shifting patients from other institutes to MH care facility. But in the case of minors, there is a difficulty as regarding who is in charge of this as MHRBs are not there.

Children cannot be admitted in adult wards, but most govt $\mathrm{MH}$ facilities do not have such wards for children.

There are practical difficulties in managing violent pts. Seclusion and restraint of patients are banned, but such modalities have therapeutic value at least in rare situations.

The concept of relative staying with the patients is ignored in the new Act.

\section{Government Mental Health Centres (GMHCs)}

NHRC has recommended that superintendents of GMHC have to be a psychiatrist. But this is not implemented in Kerala. This is something that can be easily done. GMHCs in Kerala are now evolving into training and research centres. Hence, they may be renamed accordingly. Research must be started in GMHCs as they have a good patient load. An environment conducive to research should be created in all $\mathrm{MH}$ care facilities under government, including GMHC, MCHs etc. As the Nodal officer of Research committee at GMC Kozhikode, I can list several such barriers at different levels including financial, attitudinal and administrative. These have to be remedied.

It is heartening to highlight the importance the state government gave for strengthening the availability of $\mathrm{MH}$ care in the periphery. Family health centres are to be provided $\mathrm{MH}$ care service to detect and treat depression in the Primary Health Centre (PHC) itself. This is a laudable effort.

Starting new service focussed on areas that need our service

Palliative care services, institutions like old age homes, facilities for patients with 
developmentally disabled children and adolescents, collaboration with State Institute of correctional administration for handling $\mathrm{MH}$ issues of those in prisons and correctional homes.

Duplication of services is also leading to wastage; For example, deaddiction service is being planned and given by Excise and health departments, school mental health activities are being organised by DMHP, Social Justice and Education department. University departments conducting courses in psychology, social work etc. are also organising treatment services.

Most of these initiatives have goodwill and enthusiasm, but they may not be able to offer many benefits to patients as they lack the proper approach to diagnosis and management. We have to highlight the point that having good intentions alone cannot guarantee that patients get the best available treatments.

Hence, ideally, all efforts to offer treatment to patients should be under the leadership of a psychiatrist, accompanied by a multidisciplinary team comprising of other professionals. This only can ensure that patient care takes in in a humane environment and that interventions offered have a strong backing of evidence for efficacy and safety. As a body of qualified professionals, we should continue our efforts in this direction.

\section{REFERENCES}

1. http://apps.who.int/gho/data/node.main.MH HR?lang=en.last accessed on $2^{\text {th }}$ August 201911 $17 \mathrm{pm}$

2. Murthi RS. National Mental Health Survey of India. 2015 - 16. Indian J Psychiatry 2017; 59:216.

3. Gururaj G, Varghese M, Benegal V, Rao GN, Pathak K, Singh LK, et al. and NIMAHNS collaborators group. National Mental Health Survey of India, 2015 - '16 Prevalence, pattern and Outcomes. Bengaluru, National Institute of Mental Health and Neurosciences, NIMHANS Publication No. 129, 2016.

4. Gururaj G, Varghese M, Benegal V, Rao GN, Pathak K, Singh LK, et al. and NIMAHNS collaborators group. National Mental Health Survey of India, 2015 - '16 - Prevalence, pattern and Outcomes. Bengaluru, National Institute of Mental Health and Neurosciences, NIMHANS Publication No. 130, 2016.

5. Shibukumar TM, Thavody J, National Mental Health Survey of India, 2015 - '16: Kerala State Report, IMHANS, Kozhikode, Kerala 2017.

6. https://www.rcpsych.ac.uk/become-apsychiatrist/choose-psychiatry/what-ispsychiatry/types-of-psychiatrist last accessed on 28th August 2019 at 1143 pm

7. https://www.psychiatry.org accessed on $28^{\text {th }}$ August 2019 at 1145 pm 